\title{
Molecular marker heterozygosities and genetic distances as correlates of production traits in $\mathrm{F}_{1}$ bovine crosses
}

\author{
Daniella Tambasco-Talhari ${ }^{1}$, Maurício Mello de Alencar ${ }^{2}$, Cláudia Cristina Paro de Paz ${ }^{3}$, \\ Geraldo Maria da $\mathrm{Cruz}^{2}$, Armando de Andrade Rodrigues ${ }^{2}$, Irineu Umberto Packer ${ }^{4}$, \\ Luiz Lehmann Coutinho ${ }^{4}$ and Luciana Correia de Almeida Regitano ${ }^{2}$ \\ ${ }^{1}$ Universidade Federal de São Carlos, São Carlos, SP, Brazil. \\ ${ }^{2}$ Instituto de Zootecnia, Nova Odessa, SP, Brazil. \\ ${ }^{3}$ Embrapa - Centro de Pesquisa de Pecuária do Sudeste, São Carlos, SP, Brazil. \\ ${ }^{4}$ Escola Superior de Agricultura Luiz de Queiroz, Departamento de Produção Animal, \\ Piracicaba, SP, Brazil.
}

\begin{abstract}
Several studies have investigated the relationship between heterozygosity, genetic distance and production traits. The objective of the present study was to evaluate the influence of the degree of heterozygosity and genetic distance on growth, carcass and reproductive related features in $F_{1}$ bovine crosses. We tested 10 polymorphic markers in 330 purebred cattle (Nelore, Canchim, Aberdeen Angus and Simental) and 256 crossbred cattle belonging to four crossbred groups. Individual heterozygosities $\left(H_{i}\right)$ and multilocus genetic similarity $\left(D_{m}\right)$ were estimated and used in correlation analysis against individual phenotypic measurements. Significant $(p<0.05) \mathrm{H}_{\mathrm{i}}$ effects occurred for birth weight, 15 to 18 month weight, hot carcass weight and longissimus rib eye area. The extent to which increased heterozygosity $(\Delta H)$ in $F_{1}$ crosses can be predicted from the genetic distance of parental breeds was also investigated using Nei's standard genetic distance $\left(D_{s}\right)$ and standard heterozygosity $\left(H_{s}\right)$. High correlations were found between $\Delta H_{i}, \Delta H_{s}$ and the $D_{s}$ of the parental breeds. Our results suggest that heterozygosity of the ten molecular markers used in this study may affect live weight during at least one growth phase. Parental genetic distance was a suitable predictor of the degree of progeny heterozygosity.
\end{abstract}

Key words: bovine crosses, molecular markers, heterozygosity, genetic distance, production traits.

Received: January 21, 2004; Accepted: August 18, 2004.

\section{Introduction}

The selection of suitable sires for the production of the first filial generation $\left(\mathrm{F}_{1}\right)$ is an important prerequisite for the success of any breeding program, but this is complicated by the fact that classic sire selection relies on the evaluation of the phenotypic value of the progeny which is time-consuming for large farm animals. An essential assumption underlying the prediction of hybrid performance is the correlation between heterozygosity and heterosis and in recent years molecular markers have been proposed for the prediction of heterosis and genetic relationship studies of both animal and plant species.

Several studies have investigated the relationships between genetic distance, degree of heterozygosity and production traits in populations of both feral and domesti-

Send correspondence to Luciana Correia de Almeida Regitano. Embrapa Sudeste Centro de Pesquisa Pecuária, Caixa Postal 339, 13560-970 São Carlos, SP, Brazil. E-mail: luciana@cppse. embrapa.br. cated animal and plant species. Many of these studies have shown positive correlations between heterozygosity at a small number of marker loci and traits related to fitness (Pierce and Mitton, 1982; Garton et al., 1984; Stuber et al., 1992; Xiao et al., 1995), although negative correlations have also been reported (Zhang et al., 1996). When the correlation involves heterozygosity based on allozymes it is difficult to distinguish between the direct effects of the allozyme loci and their influence as neutral markers (Pogson and Zouros, 1994), because of which polymorphisms such as microsatellites and blood groups, that are not subject to direct selection, are normally used. This approach is consistent with the associative overdominance hypothesis that predicts that the cause of correlation is not specific to the type of genetic marker used. The use of markers associated with production traits (i.e. commercially desirable traits) has been proposed by Charcosset et al. (1991) to strengthen the accuracy of prediction because any correlation would arise from the associated effect of 
each marker locus. Regarding allele number, monomorphic or nearly monomorphic loci should be avoided due to the low probability that they will affect individual heterozygosities and the fact that a lower number of polymorphic systems can provide the same information (Cepica et al., 1995). If microsatellites are used, it is important to verify that Mendelian allele segregation is occurring, due to the high occurrence of null alleles (Eggleston-Stott et al., 1997) and preferential amplification (Rodriguez et al., 2001), and in both cases the non-detectable alleles must be considered in the heterozygosity estimate.

As far as we know there have been no previous reports of studies on bovines concerning parental genetic distance, heterozygosity and production traits. The objective of the work presented in this paper was to rectify this lack of information by investigating the relationship among parental genetic distance, heterozygosity and production traits (growth, carcass and reproductive related features) in F1 bovine crosses.

\section{Material and Methods}

\section{Experimental conditions}

The animals used in this study resulted from the following crosses: Nelore (NE) cows mated to five Aberdeen Angus (AN) bulls (TA crossbred group, number of progeny $\left(\mathrm{N}_{\mathrm{p}}=72\right.$ ), five Canchim (CN) bulls ( $\mathrm{RC}$ crossbred group, $N_{p}=74$ ), four Simmental (SI) bulls (TS crossbred group, $\mathrm{N}_{\mathrm{p}}=65$ ) and two Nelore (NE) bulls (NI crossbred group, $\mathrm{N}_{\mathrm{p}}=44$ ), totaling 256 progeny. Offspring belonging to the TA, RC and TS genetic groups were born in 1998 and 1999 while NI offspring were born in 1999 only. The Nelore cows used in the crosses were from several farms and represented a sample of the Brazilian herd. The same cows were used in both reproductive periods (except for some replacements) and their ages at calving ranging from 3.4 to 17.6 years (average 6.6 years). Cows grazed on fertilized Brachiaria brizantha pastures and received supplementary sugarcane during the winter. Calves received a concentrate ration limited to $1.5 \mathrm{~kg}$ per day and were weaned between 5 and 8 months of age. After weaning the calves grazed fertilized Cynodon dactylon (coastcross) grass during the raining season, supplemented with $3 \mathrm{~kg}$ concentrate per day plus a complete mineral mixture or with only a complete mineral mixture. During the dry season, twelve-month old males were divided into two blocks according to body weight and fed in feedlot while heifers grazed on fertilized Cynodon dactylon and received sugarcane and concentrate as a supplement.

The restriction fragment length polymorphisms (RFLPs) used were as follows: $\kappa$-casein (LGB)-Hinfl (35.5 cM on Bos taurus chromosome 6 - BTA 6) (Medrano and Cordova, 1990); $\beta$-lactoglobulin (LGB) -HaeIII (108.7 on BTA 11) (Ron et al., 1994); growth hormone (GH)-AluI (65.7 cM on BTA19) (Lucy et al., 1993); and the microsatellites BM8246 (76.2 cM on BTA 1) (Stone et al., 1995), BM1224 (51.2 cM on BTA4) (Bishop et al., 1994), $B M 1329$ (35.5 cM on BTA 6), BM7160 (0 cM on BTA 7), $B M 6026$ (6.7 cM on BTA 5), CSFM50 (23.0 cM on BTA 2) (Barendse et al., 1997) and TEXAN15 (77.2 cM on BTA 5) (Burns et al., 1995). Except for BM6026,TEXAN15, $B M 1329$ and CSN3 all the markers were on different chromosomes.

\section{Statistical analysis}

Allele frequencies were obtained by direct counting (Weir, 1996) and heterozygosity measured as the mean standard heterozygosity $\left(H_{S}\right)$ calculated over all loci (Weir, 1996) and the individual heterozygosity $\left(H_{i}\right)$, estimated as the proportion of heterozygote loci over the ten loci in an individual animal (Mitton and Pierce, 1980). Since there was evidence for at least one null allele at the BM1224 locus segregating in the Nelore population (Tambasco et al., 2000), segregation analysis was employed to detect whether homozygotes should or should not be considered heterozygotic for the null allele. The increase in heterozygosity (Cepica et al., 1995) of the progeny in relation to the mean heterozygosity of the two parental populations $\left(\Delta H_{s}\right)$ or individuals $\left(\Delta H_{i}\right)$ were calculated as $\Delta H \%=\left(H_{F 1}-H_{P}\right) \times 100 / H_{P}$, where $H_{F 1}$ is either the $H_{s}$ or the mean of $H_{i}$ in the progeny of a given cross and $H_{P}$ is the arithmetic mean of $H_{s}$ or $H_{i}$ of the parental populations. Nei's standard genetic distance (Nei, 1972), based on allele frequencies estimated from 50 unrelated animals of each breed (Vasconcellos et al., In press), was used to determine the genetic distances between breeds $\left(D_{s}\right)$. The genetic distance between individuals was calculated using the method developed by Bowcock et al. (1994) and Ciampolini et al. (1995) based on pair wise inter-individual comparisons resulting in a multilocus genetic similarity value complementary to the multilocus genetic distance $\left(D_{m}\right)$. The $H_{i}$ and $D_{m}$ parameters allowed the correlation of each individual heterozygosity and genetic distance value with the corresponding phenotypic measure. These measures were: birth weight (BW); weaning weight (WW); twelve subsequent weight measurements from 230 days (W1) to about 580 days (W12); body weight at first calving (W1C) and estrus (W1E); and the carcass traits hot carcass weight (HCW), backfat thickness (RFT), longissimus rib eye area (REA) and carcass yield (CY). For both sexes, heterozygosity effects on body weight (BW, WW and W1 to W12) were analyzed using the SAS (Statistical Analysis System) program (Carry, 2000) and the GLM (General Linear Models) procedure using the statistical model $Y_{i j k l m n}=\mu+G G_{i}+S_{j}+T_{k}$ $+A_{l}+Y B_{m}+b\left(H_{i}\right)+e_{i j k l m n}$, where $\mathrm{y}_{\mathrm{ijk} k m n}$ represents the trait evaluated on the $i j k l m n^{\text {th }}$ animal; $\mu$ is the overall mean for each trait; $G G_{i}, S_{j}, T_{k}, A_{l}$, and $Y b_{m}$ are classificatory fixed effects associated with the $i^{\text {th }}$ genetic group, the $j^{\text {th }}$ sex, the $k^{\text {th }}$ nutritional treatment, the $l^{\text {th }}$ age and the $m^{\text {th }}$ year of birth; $b$ is the linear regression for the individual degree of 
heterozygosity $H_{i}$; and $e_{i j k l m n o}$ is the random error associated with the $i j k l m n^{\text {th }}$ observation. The same model was used to assess the influence of multilocus genetic distance.

For reproductive traits (W1C and W1E), the GLM procedure used a model comprising all the effects described above with the exception of the sex effect. Carcass composition traits were analyzed considering genetic group, nutritional treatment, year of birth and feedlot block with the heterozygosity or multilocus genetic similarity as sources of variation. Pearson correlation coefficients were calculated for the $\Delta H_{s}, \Delta H_{i}, D_{s}$ and $D_{m}$ variables using the CORR procedure of the SAS program (SAS, 2001).

\section{Results}

\section{Heterozygosity and genetic distance}

Segregation analysis revealed the presence of null alleles for the BM1224 microsatellite in the Nelore females and this had to be taken into account when calculating the heterozygosity, the individual heterozygosity $\left(H_{i}\right)$ ranging from 0.2 to 0.9 and the multilocus genetic distance $\left(D_{m}\right)$ values from 0.2 to 0.7 . The mean standard heterozygosity $\left(H_{s}\right)$ and $H_{i}$ along with the increase in these values in the crosses $\left(\Delta H_{i}\right.$ and $\left.\Delta H_{s}\right)$ are presented in Table 1.

The Pearson correlation analysis of the relationship between the genetic distances of the parental breeds $\left(D_{m}\right.$, $\left.D_{s}\right)$ and the increase in heterozygosity $\left(\Delta H_{s}, \Delta H_{i}\right)$ of their crosses is summarized in Table 2. Despite their high values the correlation coefficients between the multilocus genetic distance $\left(D_{m}\right)$ and $\Delta H_{s}$ and $\Delta H_{i}$ were not significant, although high correlation values were detected between the genetic distances between breeds $\left(D_{s}\right)$ and $\Delta H_{s}$ and $\Delta H_{i}$ $(\mathrm{p}<0.05)$. These results were to be expected because the correlation between $\Delta H_{s}$ and $\Delta H_{i}$ was $0.97(\mathrm{p}<0.05)$. No correlation was found between the $D_{m}$ and $D_{s}$ genetic distances.

\section{Effect of individual heterozygosity and multilocus genetic distance on phenotypic traits.}

The $H_{i}$ data comprised only animals known to be heterozygotes or homozygotes as confirmed by segregation analysis. Results of the ANOVA for the various weight measures and carcass composition traits are summarized in Tables 3, 4 and 5. With the exception of body weight (BW) and carcass yield (CY), significant genetic group effects $(p<0.01)$ were verified for all traits but this was to be expected because the four sire breeds used in the crosses are different in body size and weight. At each phenotypic measure both the age and sex of the animal significantly affected all weights except for BW $(\mathrm{p}<0.01)$. When included in the analysis, nutritional supplementation had a significant effect $(p<0.01)$ on all characteristics except for body weight at first calving (W1C) and carcass composition traits. A birth year effect was observed for most traits ex-
Table 1 - Standard $\left(H_{s}\right)$ and individual $\left(H_{i}\right)$ heterozygosity for all the genetic groups and the increase in percentage for these parameters $\left(\Delta H_{i} \%\right.$, $\left.\Delta H_{s} \%\right)$ in the progeny compared with the mean of the two parental populations.

\begin{tabular}{lcccc}
\hline & $H_{s}$ & $\Delta H_{s} \%$ & $H_{i}$ & $\Delta H_{i} \%$ \\
\hline Sire breeds & & & & \\
Canchim (CN) & 0.596 & - & 0.570 & - \\
Simental (SI) & 0.558 & - & 0.560 & - \\
A. Angus (AN) & 0.530 & - & 0.520 & - \\
Nelore (NE) & 0.459 & - & 0.480 & - \\
& & & & \\
Dam breed & & & & \\
Nelore (NE) & 0.459 & - & 0.480 & - \\
& & & & \\
Crossbred groups & & & & 18.1 \\
CN x NE (RC) & 0.596 & 13.09 & 0.620 & 21.2 \\
SI x NE (TS) & 0.607 & 19.49 & 0.630 & 30.0 \\
AN x NE (TA) & 0.643 & 30.16 & 0.650 & 0 \\
NE x NE (NI) & 0.469 & 2.18 & 0.480 & \\
\hline
\end{tabular}

cept BW, W1, W12, W1C, backfat thickness (RFT), longissimus rib eye area (REA) and carcass yield (CY).

At about 15 to 18 months $H_{i}$ had a significant effect $(\mathrm{p}<0.05)$ on BW, W10, W11 and W12, but it should be noted that at these ages the sample was composed mainly of heifers because bulls were gradually slaughtered for carcass composition analysis during the experiment and this is also the reason why the number of phenotypic measurements declined during the course of the study. Despite this, the fitness model $\left(\mathrm{R}^{2}\right)$ for these traits was high $(0.77$ to $0.85)$. The $H_{i}$ regression coefficient for BW, W10, W11 and W12 indicated that each heterozygote locus in the 10 analyzed contributed with an increase of $0.437 \mathrm{~kg}$ for BW, 4.42 $\mathrm{kg}$ for W10, $4.22 \mathrm{~kg}$ for W11 and $4.53 \mathrm{~kg}$ for W12, as calculated from the regression analysis. For carcass composition traits, $H_{i}$ showed a significant effect on hot carcass weight (HCW) and REA ( $\mathrm{p}<0.05)$, with the regression coefficient indicating an increase of $63 \mathrm{~g}$ for HCW and $1.89 \mathrm{~cm}^{2}$ for REA for each heterozygote locus.

Although both genetic group and age significantly affected weight at estrus W1E and W1C $(\mathrm{p}<0.05)$ these re-

Table 2 - Pearson correlation coefficients among the multilocus genetic distance $\left(D_{m}\right)$, Nei's standard genetic distance $\left(D_{s}\right)$, the increase in individual and standard heterozygosities of the crosses $\left(\Delta H_{i}, \Delta H_{s}\right)$.

\begin{tabular}{lcccc}
\hline & $D_{m}$ & $D_{s}$ & $\Delta H_{s}$ & $\Delta H_{i}$ \\
\hline$D_{m}$ & - & & & \\
$D_{s}$ & 0.85 & - & & \\
$\Delta H_{s}$ & 0.84 & $0.95^{*}$ & - & \\
$\Delta H_{i}$ & 0.94 & $0.96^{*}$ & $0.97^{*}$ & - \\
\hline
\end{tabular}

$* p<0.05$. 
Table 3 - Summary of analysis of variance (ANOVA) for birth weight (BW), weaning weight (WW) and the five subsequent weights (W1, W2, W3, W4 and W5).

\begin{tabular}{|c|c|c|c|c|c|c|c|c|}
\hline \multirow[b]{2}{*}{ Source of variation } & \multirow[b]{2}{*}{ Df } & \multicolumn{7}{|c|}{ Mean square } \\
\hline & & BW & WW & W1 & W2 & W3 & W4 & W5 \\
\hline Genetic group & 3 & 36.97 & $9143.80 * *$ & $10255.28^{* *}$ & $12027.67 * *$ & $12797.04 * *$ & $14858.48^{* *}$ & $17068.57^{* *}$ \\
\hline Sex & 1 & 19.14 & $11342.96 * *$ & $38.07 * *$ & $26472.97 * *$ & $35353.96^{* *}$ & $36930.88 * *$ & $50414.98 * *$ \\
\hline Nutritional treatment & 1 & - & - & - & $8469.03 * *$ & $35404.41 * *$ & $72417.67 * *$ & $109171.80 * *$ \\
\hline Age & 1 & - & $69214.99 * *$ & $84872.36^{* *}$ & $73099.23 * *$ & $100673.77 * *$ & $120009.39 * *$ & $112348.48 * *$ \\
\hline Year of birth & 1 & 19.81 & $10298.91^{* *}$ & 38.08 & $4503.75^{* *}$ & $25031.80 * *$ & $36199.98 * *$ & $74025.34 * *$ \\
\hline Individual heterozygosity & 1 & $71.08^{*}$ & 83.01 & 684.84 & 734.21 & 43.51 & 20.99 & 3.60 \\
\hline Error (Df) ${ }^{\&}$ & - & $14.80(236)$ & $458.67(228)$ & $427.71(210)$ & 407.08 (209) & $436.29(207)$ & $488.01(207)$ & $617.12(204)$ \\
\hline
\end{tabular}

${ }^{\&}$ Degrees of freedom.

$* \mathrm{p}<0.05 . *{ }^{*} \mathrm{p}<0.01$

Table 4 - Summary of analysis of variance (ANOVA) for weights W6, W7, W8, W9, W10, W11 and W12.

\begin{tabular}{lcrrrrrrr}
\hline & & \multicolumn{5}{c}{ Mean square } \\
\cline { 3 - 8 } Source of variation & Df & W6 & W7 & W8 & W9 & W10 & W11 \\
\hline Genetic group & 3 & $20441.18^{* *}$ & $24594.55^{* *}$ & $26536.19^{* *}$ & $31331.68^{* *}$ & $18265.84^{* *}$ & $16009.52^{* *}$ & $18160.82^{* *}$ \\
Sex & 1 & $146717.43^{* *}$ & $281891.84^{* *}$ & $580376.73^{* *}$ & $718789.31^{* *}$ & $320447.77^{* *}$ & $294161.66^{* *}$ & $61937.16^{* *}$ \\
Nutritional treatment & 1 & $99783.93^{* *}$ & $89449.63^{* *}$ & $57271.79^{* *}$ & $32020.80^{* *}$ & $30011.20^{* *}$ & $23273.44^{* *}$ & $21170.66^{* *}$ \\
Age & 1 & $93915.05^{* *}$ & $105659.95^{* *}$ & $102313.28^{* *}$ & $80632.71^{* *}$ & $47035.22^{* *}$ & $28299.83^{* *}$ & $21498.17^{* *}$ \\
Year of birth & 1 & $36934.81^{* *}$ & $30912.89^{* *}$ & $27303.24^{* *}$ & $3520.40^{*}$ & 2736.13 & $11452.53^{* *}$ & 777.08 \\
Individual heterozygosity & 1 & 167.92 & 356.51 & 1534.70 & 2534.19 & $3741.26^{*}$ & $3119.85^{*}$ & $3107.84^{*}$ \\
Error (Df) & - & $777.47(180)$ & $852.99(180)$ & $957.56(177)$ & $833.43(162)$ & $739.62(119)$ & $674.76(110)$ & $620.74(98)$ \\
\hline
\end{tabular}

${ }^{\&}$ Degrees of freedom.

${ }^{*} \mathrm{p}<0.05 . *{ }^{*} \mathrm{p}<0.01$

Table 5 - Summary of analysis of variance (ANOVA) for weight at first calving (W1C), weight at first estrum (W1E), hot carcass weight (HCW), backfat thickness (RFT), longissimus rib eye area (REA) and carcass yield (CY).

\begin{tabular}{|c|c|c|c|c|c|c|c|}
\hline \multirow[b]{2}{*}{ Source of variation } & \multirow[b]{2}{*}{ Df } & \multicolumn{2}{|c|}{ Reproductive traits } & \multicolumn{4}{|c|}{ Carcass traits } \\
\hline & & W1C & W1E & $\mathrm{HCW}$ & RFT & REA & $\mathrm{CY}$ \\
\hline Genetic group & 3 & $10291.85^{* *}$ & $7962.18^{* *}$ & $5754.88^{* *}$ & $12.78 * *$ & $497.14 * *$ & 0.95 \\
\hline Treatment & 1 & 910.87 & $31023.48 * *$ & 533.31 & 9.89 & 44.56 & 0.97 \\
\hline Age & 1 & $9096.35^{* * *}$ & $86771.49 * *$ & - & - & - & - \\
\hline Year of birth & 1 & 20.94 & $16492.69 * *$ & 272.28 & $63.86^{* *}$ & $495.13 *$ & 4.39 \\
\hline Block & 1 & - & - & 162.08 & $26.48 * *$ & 39.45 & 15.27 \\
\hline Individual heterozygosity & 1 & 1427.20 & 279.56 & $4398.55^{* *}$ & 0.84 & $401.97 *$ & 2.11 \\
\hline Error $(D f)^{\&}$ & - & $1365.17(89)$ & $630.70(95)$ & $842.33(78)$ & $2.92(78)$ & $82.93(78)$ & $7.59(78)$ \\
\hline
\end{tabular}

${ }^{\&}$ Degrees of freedom.

${ }^{*} \mathrm{p}<0.05 . *{ }^{*} \mathrm{p}<0.01$

productive characteristics were unaffected by $H_{i}$ or $D_{m}$. Multilocus genetic distance $\left(D_{m}\right)$ did not affect any of the traits examined.

\section{Discussion}

Two different measures of genetic diversity were used, the standard heterozygosity $\left(H_{s}\right)$ representing the fre- quency of heterozygotes observed in one population or sample over all loci analyzed (Weir, 1996) and the individual heterozygosity $\left(H_{i}\right)$ as estimated by the proportion of heterozygote loci over the ten loci analyzed (an individual measure). The Nelore breed showed the lowest $H_{s}$ and $H_{i}$ genetic diversity of the parental breeds, possibly related to the small number of founder animals in the Brazilian herd, 
whereas the highest $H_{s}$ and $H_{i}$ genetic diversity was observed with the Canchim breed, probably because this is a composite breed consisting of 5/8 Charolais plus 3/8 Zebu. Despite the infrequent use of $H_{i}$, the high correlation value between $\Delta H_{s}$ and $\Delta H_{i}$ indicates that the individual heterozygosity $\left(H_{i}\right)$ is a suitable measure of genetic diversity.

We used two methods to calculate the genetic distance between the breeds, Nei's standard genetic distance $\left(D_{s} ; \mathrm{Nei}, 1972\right)$ which is widely used in the literature and takes into account evolutionary forces, and the multilocus genetic distance $\left(D_{m}\right.$; complementary to the multilocus genetic similarity) which is based on pair wise interindividual comparisons (Bowcock et al., 1994; Ciampolini et al., 1995) and which dispenses with the need to calculate previous allele frequencies and thus allows the assessment of the genetic distance between individuals of the same breed. Ciampolini et al. (1995) used 17 microsatellites to analyze the inter and intrapopulation genetic variability of four Italian cattle breeds and confirmed the utility of $D_{m}$ and its agreement with classical genetic distances but we did not find the same agreement in our study because although the Pearson's correlation coefficient was high it was not significant. To increase the sensitivity of the method and enable a better estimate the number of loci examined should be as high as possible. In our study the $H_{i}$ and $D_{m}$ parameters were chosen to investigate the effects of heterozygosity and genetic distance on production traits since these parameters allow for regression analysis for individual animals. This approach was considered better than working with the average values for these parameters in the populations studied.

Previous studies have investigated the relationship between production traits, parental genetic distance and heterozygosity, and it is accepted that such relationships are related to heterosis, with several reports suggesting a strong correlation between molecular-marker heterozygosity and hybrid performance (Garton et al., 1984; Stuber et al., 1992; Xiao et al., 1995) although, according to Zhang et al. (1996), this relationship can be variable depending on the genetic material in question and the complexity of the genetic basis of heterosis. Numerous reports of both positive and negative correlations between heterozygosity and fitness-related traits have been published for many different organisms. Pierce and Mitton (1982), for example, observed significant and positive correlations between individual heterozygosity and the size of tiger salamanders while Smith et al. (1990) suggested that it was possible to use genetic distance to predict combinations of maize lineages that would result in high grain-yields, although Melchinger et al. (1990) found that in maize the correlations were two small to be of predictive value. Cepica et al. (1995) found a high correlation between increased heterozygosity in pig crosses and the genetic distance between the parental lines while Gregory et al. (1994) demonstrated that in beef cattle crossbreeding systems the retention of heterosis was approximately proportional to the expected retention of heterozygosity for most traits.

The molecular basis of heterosis could be related to overdominance or dominance events. If overdominance was the cause the superior performance of heterozygotes could be described as a manifestation of physiological differences between heterozygotes and parental homozygotes which cause variations in their metabolic rates (Trehan and Gill, 1987). The correlation between heterozygosity and phenotype can not arise from single-locus dominance because homozygotes for the dominant allele would share the same phenotype as heterozygotes (Deng and Fu, 1998). If multiple-loci were involved a correlation might exist because it is unusual to have two parental lines homozygotes for alternate alleles at each locus, with one line harboring all the dominant alleles and the other harboring all the recessive alleles.

In a simulation study using natural populations, Mitton and Pierce (1980) found that the estimation of individual heterozygosity obtained from as few as a dozen randomly chosen loci may reflect the heterozygosity determined by 100 independent loci, while Cepica et al. (1995) found that in polymorphic systems a smaller number of polymorphic loci would be sufficient to detect differences in heterozygosities between populations.

Body weight traits can be considered as essentially additive traits since they usually have high heritability and low heterosis resulting from crosses. However, growth at different ages may be the result of the action of different genes that could differ in average gene action, which could account for the fact that $H_{i}$ was significant during only one growth period (W10-W12). In marine bivalves, David et al. (1995) found that there was a significant positive correlation between heterozygosity and the rate of weight gain in the first half of the growth curve but no correlation with mature weight. While Cheverud (2002), investigating quantitative trait loci affecting growth in mice, found that variability in different growth periods and physiological status are controlled by independent sets of genes. In our study, the positive and significant $H_{i}$ effect on hot carcass weight (HCW) and longissimus rib eye area (REA) supports the result obtained for live weight because live weight affects carcass weight. To assess whether the effect of $H_{i}$ on REA was related to carcass weight we corrected REA to account for carcass weight (REA/HCW) and when this was done the effects of $H_{i}$ on REA did not remain, indicating that $H_{i}$ affected total growth and not just REA. Similar results were obtained when carcass weight was the covariant for carcass composition traits (data not shown). The regression coefficients for BW, W10-W12 and REA showed a high weight increment per heterozygote locus. In addition, the percentage of phenotypic variation due to the level of heterozygosity ranged from $0.6 \%$ (W10 and W11) to $2 \%$ (BW) for live weights and was about $4 \%$ for REA and $\mathrm{HCW}$. This is an interesting finding when considering the 
limited number of loci and it is hard to predict what the results would be if more markers had been used.

Our results suggest that heterozygosity at a limited number of polymorphic markers may affect live weight in at least one growth period. Whether this is an effect of general heterozygosity or the effect of heterozygosity at specific loci is still unclear since at least one direct effect has been detected for the analyzed loci (Tambasco et al., 2003). The $H_{i}$ parameter has shown to be a powerful tool for regression analysis and previous and present work points to the possibility of pre-selecting individuals for commercial crosses according to their heterozygosity. Also, despite the fact that multilocus genetic distance $\left(D_{m}\right)$ was not significant the hypothesis of its positive correlation with growth related traits should be investigated using a larger number of animals (increased sample size) and a greater number of markers. Moreover, our study also indicates that the genetic distance between parents is positively correlated with increased heterozygosity in the progeny and could be used, as in the present crosses, as a predictive measure for heterozygosity.

\section{Acknowledgments}

The authors wish to thank the Brazilian agencies FAPESP and $\mathrm{CNPq}$ financial support.

\section{References}

Barendse W, Vaiman D, Kemp SJ, Sugimoto Y, Armitage SM, Williams JL, Sun HS, Eggen A, Agaba M, Aleyasin SA, Band M, Bishop MD, Buitkamp J, Byrne K, Collins F, Cooper L, Coppettiers W, Denys B, Drinkwater RD, Easterday K, Elduque C, Ennis S, Erhardt G, Ferretti L, Flavin N, Gao Q, Georges M, Gurung R, Harlizius B, Hawkins G, Hetzel J, Hirano T, Hulme D, Jorgensen C, Kessler M, Kirkpatrick BW, Konfortov B, Kostia S, Kuhn C, Lenstra JA, Leveziel H, Lewin HA, Leyhe B, Lil L, Martin Burriel I, McGraw RA, Miller JR, Moody DE, Moore SS, Nakane S, Nijman IJ, Olsaker I, Pomp D, Rando A, Ron M, Shalom A, Teale AJ, Thieven U, Urquhart BGD, Vage D-I, Van De Weghe A, Varvio S, Velmala S, Vilkki J, Weikard R, Woodside C, Womack JE, Zanotti M and Zaragoza P (1997) A medium-density genetic linkage map of the bovine genome. Mamm Genome 8:29-36.

Bishop MD, Kappes SM, Keele JW, Stone RT, Sunden SLF, Hawkins GA, Solinas Toldo S, Fries R, Grosz MD, Yoo J and Beattie CW (1994) A genetic linkage map for cattle. Genetics 136:619-639.

Bowcock AM, Ruiz-Linares A, Tomfohrde J, Minch E, Kidd JR and Cavalli-Sforza LL (1994) High resolution of human evolutionary trees with polymorphic microsatellites. Nature 368:455-457.

Burns BM, Taylor JF, Herring AD, Holder MT, Collins JS, Guerra TM and Sanders JO (1995) Bovine microsatellite dinucleotide repeat polymorphisms at the TEXAN11, TEXAN12, TEXAN13, TEXAN14 AND TEXAN15 loci. Anim Genet 26:201-202.
Cepica S, Wolf J, Hojny J, Vacková I and Schroffel Jr J (1995) Relations between genetic distance of parental pig breeds and heterozygosity of their $F_{1}$ crosses measured by genetic markers. Anim Genet 26:135-140.

Charcosset A, Lefort BM and Gallais A (1991) Relationship between heterosis and heterozygosity at marker loci: A theoretical computation. Theor Appl Genet 81:571-575.

Cheverud JM (2002) Quantitative trait loci affecting postnatal growth in mice. $7^{\text {th }}$ World Congress on Genetics Applied to Livestock production, Montpellier, France.

Ciampolini R, Moazami-Goudarzi K, Vaiman D, Dillmann C, Mazzanti E, Fouley J-L, Leveziel H and Cianci, D (1995) Individual multilocus genotypes using microsatellite polymorphisms to permit the analysis of the genetic variability within and between Italian beef cattle breeds. J Anim Sci 73:3259-3268.

David P, Delay B, Berthou P and Jarne P (1995) Alternative models for allozyme-associated heterosis in the marine bivalve Spisula ovalis. Genetics 139:1719-1726.

Deng H-W and Fu Y-X (1998) Conditions for positive and negative correlations between fitness and heterozygosity in equilibrium populations. Genetics 148:1333-1340.

Eggleston-Stott ML, Delvalle A, Dileanis S, Wictum E and Bowling AT (1997) A single base transversion on the flanking region of an equine microsatellite locus affects amplification of one allele. Anim Genet 28:438-440.

Garton DW, Koehn RK and Scott TM (1984) Multiple-locus heterozygosity and the physiological energetics of growth in the coot clam, Mulinia lateralis, from a natural population. Genetics 108:445-455.

Lucy MC, Hauser SD, Eppard PJ, Krivi GG, Clark JH, Bauman DE and Collier RJ (1993) Variants of somatotropin in cattle: Gene frequencies in major dairy breeds and associated milk production. Domest Anim Endocrinol 10:325-333.

Medrano JF and Aguilar-Cordova E (1990) Genotyping of bovine kappa-casein loci following DNA sequence amplification. Biotechnology 8:144-146.

Melchinger AE, Lee M, Lamkey KR, Hallauer AR and Woodman WL (1990) Genetic diversity for restriction fragment length polymorphisms and heterosis for two diallel sets of maize inbreds. Theor Appl Genet 80:488-496.

Mitton JB and Pierce BA (1980) The distribution of individual heterozygosity in natural populations. Genetics 95:1043-1054.

Nei M (1972) Genetic Distance Between Population. American Naturalist, New York, 291 pp.

Pierce BA and Mitton JB (1982). Allozyme heterozygosity and growth in the tiger salamander, Ambystoma tigrinum. The $\mathrm{J}$ Hered 73:250-253.

Pogson GH and Zouros E (1994) Allozyme and RFLP heterozygosities as correlates of growth rate in the scallop Placopecten magellanicus: A test of the associative overdominance hypothesis. Genetics 137:221-231.

Rodriguez S, Visedo G and Zapata C (2001) Detection of errors in dinucleotide repeat typing by nondenaturing electrophoresis. Electrophoresis 22:2656-2664.

Ron M, Yoffe O, Ezra E, Medrano JF and Weller JI (1994) Determination of effects of milk protein genotyping on production traits of Israeli Holstein. J Dairy Sci 77:1106-1113.

SAS/Stat (2001) User's guide: Statistics version 8.2, Cary. 
Smith OS, Smith JSC, Bowen SL, Tenborg RA and Wall SJ (1990) Similarities among a group of elite maize inbreds as measured by pedigree, $F_{1}$ grain yield, grain yield, heterosis, and RFLPs. Theor Appl Genet 80:833-840.

Stone RT, Pulido JC, Duyk GM, Kappes SM, Keele JW and Beattie CW (1995) A small-insert bovine genomic library highly enriched for microsatellite repeat sequences. Mamm Genome 6:714-724.

Stuber CW, Lincoln SE, Wolf SE, Helentjaris T and Lander ES (1992) Identification of genetic factors contributing to heterosis in hybrid from two elite maize inbred lines using molecular markers. Genetics 132:823-839.

Tambasco DD, Jorge E, Alencar MM, Coutinho LL, Tambasco MD and Regitano LCA (2000) Evidência de alelo nulo para um loco microssatélite em uma amostra de Nelore. Genet Mol Biol 23 (suppl): 46 Congresso Nacional de Genética, Águas de Lindóia, Brasil.
Tambasco DD, Paz CCP, Tambasco-Studart M, Pereira AP, Alencar MM, Freitas AR, Coutinho LL, Packer IU and Regitano LCA (2003) Candidate genes for growth traits in beef cattle crosses Bos taurus x Bos indicus. J Anim Breed Genet 120:51-54.

Trehan KS and Gill KS (1987) Subunit interaction: A molecular basis of heterosis. Biochem Genet 25:855-862.

Weir BS (1996) Genetic Data Analysis: Methods for Discrete Population Genetic Data. 2nd edition. Sinauer Associates, Massachusetts, $445 \mathrm{pp}$.

Xiao J, Li J, Yuan L and Tanksley SD (1995) Dominance is the major genetic basis of heterosis in rice as revealed by QTL analysis using molecular markers. Genetics 140:745-754.

Zhang Q, Zhou ZQ, Yang GP, Xu CG, Liu KD and Saghai Maroof MA (1996) Molecular marker heterozygosity and hybrid performance in indica and japonica rice. Theor Appl Genet 93:1218-1224.

Associate Editor: Pedro Franklin Barbosa 